\title{
Procedimento para avaliação da qualidade do serviço de transporte fretado de funcionários por ônibus sob a ótica do usuário, empresa contratante e prestadora do serviço
}

Noéle Bissoli Perini de Souza noeleperini@hotmail.com Universidade Federal do Espírito Santo (UFES), Vitória, Espírito Santo, Brasil

Gregório Coelho de Morais Neto gregorioufes@msn.com

iversidade Federal do Espírito Santo (UFES), Vitória, Espírito Santo, Brasil

\section{Patrícia Alcântara Cardoso} profa.patriciacardoso@gmail.com (UFES), Vitória, Espírito Santo, Brasil

\author{
RESUMO
}

Este artigo tem como objetivo a proposição de um procedimento para avaliar a qualidade do serviço de transporte fretado de empregados e estabelecer uma correlação entre a visão dos agentes envolvidos - usuários, empresa contratante e prestadora do serviço. Para tanto, foi realizada uma análise dos GAPs da qualidade, ou seja, a partir de uma revisão bibliográfica pode-se levantar características que influenciam a qualidade do transporte de passageiros, e por tanto, as diferenças de suas percepções puderam ser identificadas, por meio de um experimento de campo. Dessa forma, puderam-se expor as características e percepções dos usuários, da empresa contratante e da prestadora do serviço de transporte de funcionários, bem como feita uma avaliação da qualidade do serviço de transporte fretado de empregados. Esse procedimento inova ao incluir a visão do prestador de serviço como terceiro agente no modelo. Inova também ao desdobrar o agente "cliente" em usuários e gestores do contrato e, também, a empresa contratada em motoristas e técnicos administrativos. Em consequência dessas inovações, os GAPs foram redefinidos e rearranjados no procedimento proposto.
\end{abstract}

PALAVRAS-CHAVE: Transporte fretado. Qualidade de serviços. Análise de GAP. 


\section{INTRODUÇÃO}

O transporte público de passageiros, que se enquadra no setor de serviços, apresenta grande relevância à sociedade, visto que por meio dele é possível permitir que as pessoas cheguem ao seu destino, seja trabalho, lazer, estudos, entre outros. Contudo, este tipo de serviço tem apresentado diversos problemas, tais como superlotação, congestionamentos, falta de pontualidade e disponibilidade, que dentre outras coisas, aumentam o tempo de viagem, tornando este tipo de transporte lento.

Para contornar esta situação, as grandes empresas têm contratado transporte fretado de seus funcionários, de modo a evitar os problemas existentes no sistema de transporte público e possibilitar um aumento do rendimento do funcionário. Além dos benefícios aos funcionários, as empresas ganham no que tange à redução do contingente de veículos que chegam aos seus acessos e, dessa forma, da necessidade de área de estacionamento. Ao substituir o veículo particular, o transporte fretado possibilita aos usuários a redução de consumo de combustíveis e, consequentemente, um menor impacto ao meio ambiente.

As empresas estão ainda preocupadas com a qualidade do transporte de seus funcionários. Do ponto de vista da qualidade, é importante considerar a visão de todos os atores envolvidos com o transporte fretado: usuários, empresa contratante e prestadora do serviço. Buscar compreender as diversas percepções sobre a qualidade do sistema pelos diversos atores envolvidos, do passageiro/usuário ao empresário, propiciará novas visões e medidas mais amplas que possam vir a contribuir para a melhoria do sistema como um todo.

Deste modo, percebe-se que medir e avaliar a qualidade do serviço de transporte dos funcionários pode trazer respostas tanto à empresa contratante (EC) quanto à prestadora de serviços (PS), sendo uma excelente ferramenta de relacionamento e de melhoria nos processos.

Além do fato de que ser uma tarefa complexa, existem poucos estudos realizados e modelos desenvolvidos sobre a avaliação da qualidade em serviços. Sendo assim, é importante que se desenvolvam estudos analisando os modelos existentes e propondo novas formas de avaliação.

Neste contexto, esta pesquisa busca responder as seguintes questões: quais fatores permitem avaliar a qualidade do serviço de transporte urbano de empregados por uma frota de ônibus fretada? Como avaliar a qualidade do serviço de transporte fretado de empregados sob a ótica dos agentes envolvidos - usuários, contratante e prestadora do serviço?

Com base no exposto, o objetivo deste artigo é propor um procedimento para avaliar a qualidade do serviço de transporte fretado de empregados sob a visão dos agentes envolvidos - usuários, empresa contratante e prestadora do serviço.

Este artigo está organizado em seis seções, iniciando-se com a presente introdução. Na seção 2 é apresentado um referencial teórico sobre Avaliação da Qualidade de Serviços. Na seção 3, é apresentado o resultado de um levantamento bibliográfico de atributos e características que influenciam a qualidade de transporte de passageiros por ônibus. A seção 4 disserta sobre o 
procedimento aplicado nesta pesquisa. A seção 5 apresenta os resultados das análises dos GAPs. Na sexta e última seção são apresentadas as principais conclusões.

\section{AVALIAÇÃO DA QUALIDADE DE SERVIÇOS}

Os primeiros esforços para a avaliação de serviços podem ser atribuídos ao trabalho dos pesquisadores norte-americanos Parasuraman, Zeithaml e Berry (1985), que desenvolveram o modelo, designado por Modelo Conceitual de Qualidade nos Serviços, onde se evidenciam os principais requisitos para um fornecedor atender à qualidade esperada. Este modelo apresenta as falhas ou lacunas (GAPs) que podem ocorrer numa prestação de serviço, conforme indicado na Figura 1.

Figura 1 - Modelo "GAP" de Qualidade dos Serviços

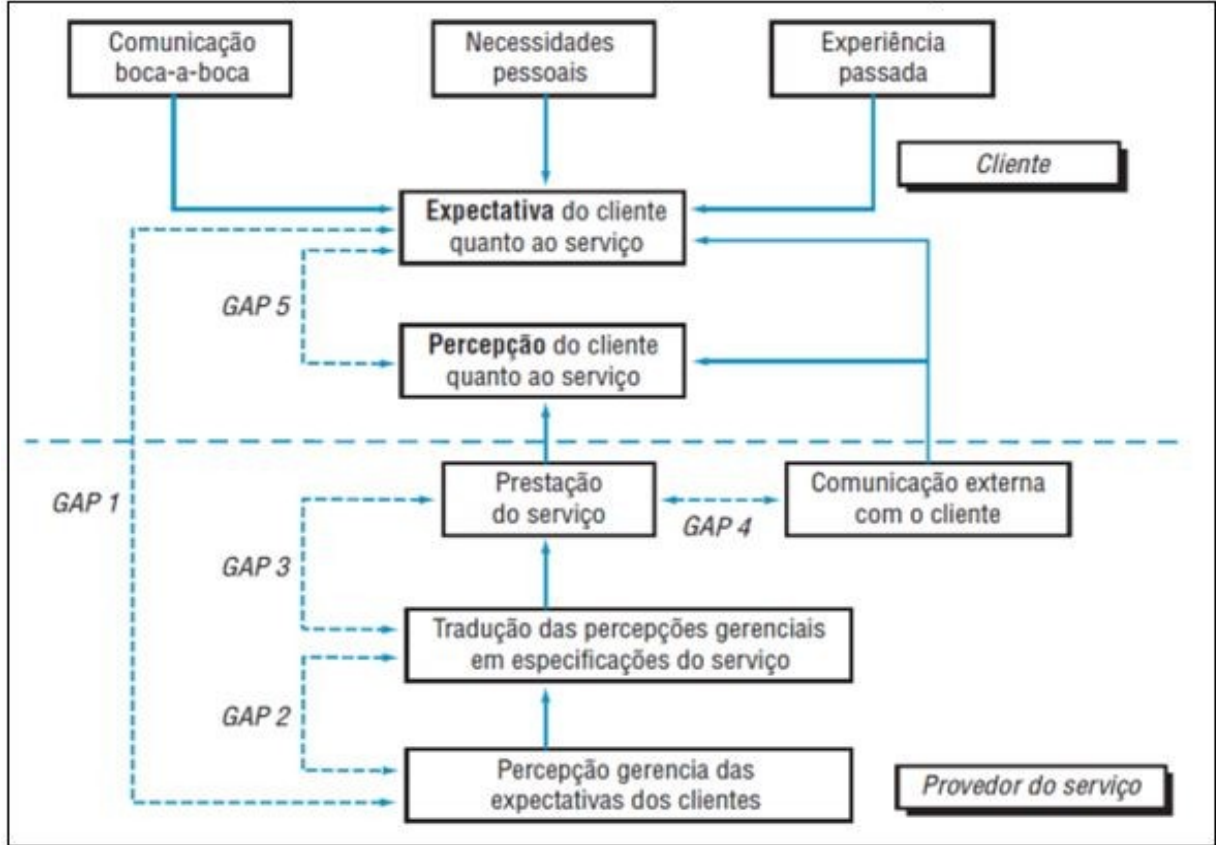

Fonte: Parasuraman (1985)

Machado, Queiroz e Martins (2006) comentam que, após comprarem e consumirem o serviço, os clientes comparam a qualidade esperada com aquilo que realmente receberam. Dessa forma, para que as empresas possam fornecer serviços com qualidade aos seus clientes, elas devem atentar para o que os satisfazem e o que os desagradam com relação aos produtos e serviços oferecidos. A satisfação dos clientes depende do equilíbrio entre as expectativas existentes e a percepção sobre os serviços fornecidos pela empresa.

O conceito da qualidade percebida pelo cliente, definido por Parasuraman et al. (1985), está baseado na comparação entre as expectativas prévias, em relação ao serviço, e as percepções reais do serviço prestado, sendo dimensionado pelo gap (lacuna) existente. Os GAPs são:

GAP 1 (Lacuna entre as expectativas do consumidor e as percepções da empresa) que resulta da diferença entre as reais expectativas dos clientes, em relação ao serviço, e a percepção que a gerência da empresa tem destas 
expectativas; GAP 2 (Lacuna entre a percepção da empresa e as especificações da qualidade do serviço), a empresa pode não ter estabelecido padrões de qualidade ou não os ter de uma forma clara e/ou realista. É preciso traduzir as expectativas do cliente em especificações de desempenho coerentes que orientem a empresa na prestação do serviço; GAP 3 (Lacuna entre as especificações da qualidade do serviço e o serviço prestado), uma vez estabelecidos, os padrões devem ser observados durante a prestação do serviço, pois podem ocorrer falhas na sua execução, que podem afetar a qualidade final; GAP 4 (Lacuna entre o serviço prestado e a comunicação externa) é a falha que surge normalmente através da propaganda ou outras formas de comunicação. Promessas exageradas influenciam as expectativas e as percepções do cliente; e GAP 5 (Lacuna entre o serviço esperado e o serviço percebido) que é a falha existente entre a expectativa do cliente, em relação ao serviço, e a sua percepção quanto ao serviço prestado. Parasuraman et al. (1985) pressupõem que o quinto gap, que é a variável que mensura a qualidade do serviço, é função dos outros quatro.

\section{ATRIBUTOS E CARACTERÍSTICAS QUE INFLUENCIAM A QUALIDADE DE TRANSPORTE DE PASSAGEIROS POR ÔNIBUS}

Segundo Alexandre (2010), o atributo pode ser conceituado como um conjunto de uma ou mais variáveis mensuráveis (quantitativas) ou não (qualitativas). A identificação dos atributos e suas características correspondentes servem de base na avaliação da qualidade de serviço no transporte e para a obtenção de um serviço de transporte qualidade.

Dentre as abordagens sobre a qualidade em transporte de passageiros por ônibus, podem ser destacadas as de Oliveira (2006), Pêgo et al. (2008), Korzenowski et al. (2008), Antunes (2009), Alexandre (2010), Nascimento e Tozi (2010), Rodrigues et al. (2010), Jammal (2010), Eboli e Mazulla (2011), Dell'Olio, Ibeas e Cecin (2011), Freitas et al. (2011), Morais (2012), Oña, Oña e Calvo (2012), Freitas (2013), Freitas e Reis (2013), De Oña et al. (2013) e Antunes e Simões (2013). O resultado das análises dessas abordagens, visando a definição dos principais atributos e de suas respectivas características que influenciam na qualidade do transporte de passageiros por ônibus, é apresentado no Quadro 1.

Quadro 1 - Atributos e características da qualidade do transporte de passageiros por ônibus

\begin{tabular}{|c|c|}
\hline Atributos & Características \\
\hline \multirow{3}{*}{ Acessibilidade } & $\begin{array}{l}\text { Condições e conservação das calçadas e } \\
\text { travessias }\end{array}$ \\
\hline & Proximidade até o ponto de ônibus \\
\hline & Configuração da rede de paradas \\
\hline \multirow{2}{*}{ Frequência de Atendimento } & Flexibilidade de horários \\
\hline & Tempo de espera no ponto de ônibus \\
\hline \multirow[t]{2}{*}{ Tempo de Viagem } & $\begin{array}{l}\text { Distância percorrida entre os locais de } \\
\text { embarque e desembarque }\end{array}$ \\
\hline & Tempo de viagem \\
\hline Lotação & Quantidade de passageiros no ônibus \\
\hline \multirow{2}{*}{ Confiabilidade } & Pontualidade (respeito aos horários) \\
\hline & Efetividade \\
\hline \multirow{2}{*}{ Segurança } & Acidentes \\
\hline & Assaltos \\
\hline
\end{tabular}




\begin{tabular}{|c|c|}
\hline & Segurança no ponto de ônibus \\
\hline \multirow{12}{*}{ Características dos Veículos } & Limpeza \\
\hline & Manutenção do veículo \\
\hline & Conforto das cadeiras \\
\hline & Conforto do veículo \\
\hline & Temperatura \\
\hline & Ruído \\
\hline & Espaço no ônibus \\
\hline & $\begin{array}{l}\text { Veículos acessíveis a portadores de } \\
\text { necessidades especiais }\end{array}$ \\
\hline & Espaço para bagagens dos passageiros \\
\hline & Facilidade de subida e descida do veículo \\
\hline & Existência de banheiro \\
\hline & $\begin{array}{l}\text { Dispositivos de segurança adequados ao } \\
\text { uso }\end{array}$ \\
\hline \multirow{5}{*}{ Características dos Locais de Parada } & Limpeza dos terminais e paradas \\
\hline & Os pontos de ônibus são agradáveis de ficar \\
\hline & $\begin{array}{l}\text { Sinalização (placas identificatórias) dos } \\
\text { pontos }\end{array}$ \\
\hline & Coberturas nos pontos \\
\hline & Assentos dos pontos \\
\hline \multirow{3}{*}{ Sistemas de Informação } & Informações nos pontos de ônibus \\
\hline & Informações existentes nos veículos \\
\hline & $\begin{array}{l}\text { Ter canais de comunicação para o cliente } \\
\text { elogiar, reclamar e sugerir }\end{array}$ \\
\hline \multirow{4}{*}{ Conectividade } & Rapidez para trocar de ônibus \\
\hline & Local adequado para fazer a conexão \\
\hline & $\begin{array}{l}\text { Opções de destino (para diversas partes da } \\
\text { cidade) }\end{array}$ \\
\hline & $\begin{array}{l}\text { Indicação dos locais de transferência para } \\
\text { outras linhas }\end{array}$ \\
\hline \multirow{5}{*}{ Comportamento dos Operadores } & Educação do motorista \\
\hline & $\begin{array}{l}\text { Tratamento dado aos passageiros pelo } \\
\text { cobrador }\end{array}$ \\
\hline & Eficiência do motorista \\
\hline & $\begin{array}{l}\text { Segurança passada pelos motoristas ao } \\
\text { dirigir }\end{array}$ \\
\hline & Cortesia dos funcionários \\
\hline Tarifa & Preço da Passagem \\
\hline
\end{tabular}

Fonte: Elaborado pelos autores

\section{PROCEDIMENTO PROPOSTO}

Para a apresentação do Procedimento Proposto, inicialmente apresenta-se, na Figura 2, o Método de Pesquisa utilizado. 
Figura 2 - Método da Pesquisa

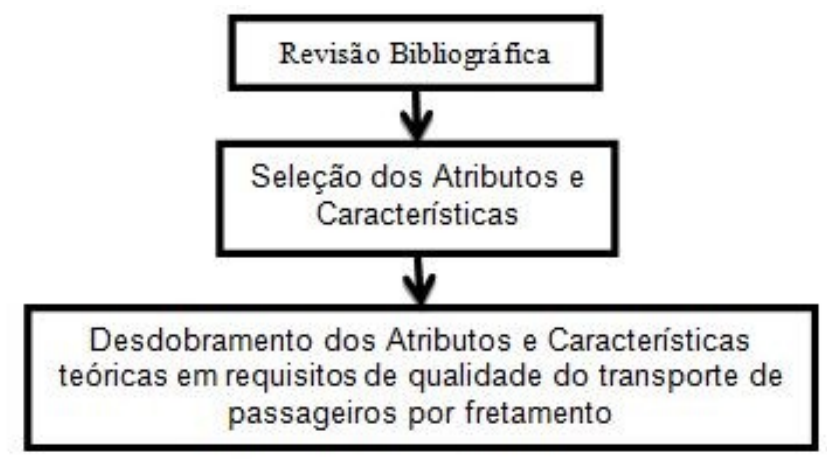

Fonte: Elaborado pelos autores

A partir da aplicação do Método de Pesquisa, pode-se construir a primeira versão do questionário com base na revisão bibliográfica sobre atributos e características da qualidade do transporte de passageiros por ônibus. Assim, foi aplicado o desdobramento da qualidade (QFD) para que os atributos ( $1^{\circ}$ nível) e as suas respectivas características $\left(2^{\circ}\right.$ nível) pudessem ser desdobradas em questões (3ำ nível) com uma linguagem acessível aos entrevistados. Por isso, o Quadro 1 precisou ser revisado para adaptá-lo ao transporte por fretamento, o que gerou o Quadro 2. Dessa maneira, pode-se reduzir significativamente o número de questões a serem respondidas. As 43 características consolidadas para o transporte de passageiros por ônibus reduziram-se a 23 características que explicam a qualidade para o transporte fretado de passageiros. Essa redução é relevante para a extensão do questionário, tem impacto direto no tempo de sua aplicação, que não poder ser muito longo, pois pode ocasionar a recusa do entrevistado em respondê-lo.

Quadro 2 - Atributos e características da qualidade do transporte de passageiros por uma frota de ônibus fretada

\begin{tabular}{|l|l|}
\hline \multicolumn{1}{|c|}{ Atributos } & \multicolumn{1}{c|}{ Características } \\
\hline \multirow{4}{*}{ Acessibilidade } & Proximidade até o ponto de ônibus \\
\cline { 2 - 2 } & Configuração da rede de paradas \\
\hline Tempo de Viagem & Tempo de viagem \\
\hline Lotação & Quantidade de passageiros no ônibus \\
\hline Confiabilidade & Pontualidade (respeito aos horários) \\
\hline \multirow{5}{*}{ Segurança } & Acidentes \\
\cline { 2 - 2 } & Assaltos \\
\hline \multirow{5}{*}{ Características dos Veículos } & Limpeza \\
\cline { 2 - 2 } & Manutenção do veículo \\
\cline { 2 - 2 } & Conforto das cadeiras \\
\cline { 2 - 2 } & Temperatura \\
\cline { 2 - 2 } & Espaço no ônibus \\
\cline { 2 - 2 } & $\begin{array}{l}\text { Veículos acessíveis a portadores de } \\
\text { necessidades especiais }\end{array}$ \\
\cline { 2 - 2 } & Espaço para bagagens dos passageiros \\
\cline { 2 - 2 } & Facilidade de subida e descida do veículo \\
\cline { 2 - 2 } & Existência de banheiro \\
\hline
\end{tabular}




\begin{tabular}{|l|l|}
\hline \multirow{4}{*}{ Sistemas de Informação } & $\begin{array}{l}\text { Dispositivos de segurança adequados ao } \\
\text { uso }\end{array}$ \\
\hline \multirow{2}{*}{ Conectividade } & Informações existentes nos veículos \\
\cline { 2 - 2 } & $\begin{array}{l}\text { Ter canais de comunicação para o cliente } \\
\text { elogiar, reclamar e sugerir }\end{array}$ \\
\hline \multirow{2}{*}{ Comportamento dos Operadores } & Rapidez para trocar de ônibus \\
\cline { 2 - 2 } & Local adequado para fazer a conexão \\
\hline & $\begin{array}{l}\text { Educação do motorista } \\
\text { dirigir }\end{array}$ \\
\hline
\end{tabular}

Fonte: Elaborado pelos autores

A estrutura dos questionários é composta por uma pergunta fechada referente ao nível de importância e outra ao nível de satisfação, para cada uma das características do serviço de transporte. As respostas são associadas em uma escala numérica ordinal de 1 (Mínima Importância; e Satisfação - Péssima) até 5 (Máxima Importância; e Satisfação - Muito Bom). O procedimento proposto para atender ao objetivo é apresentado na Figura 3.

Figura 3 - Procedimento proposto

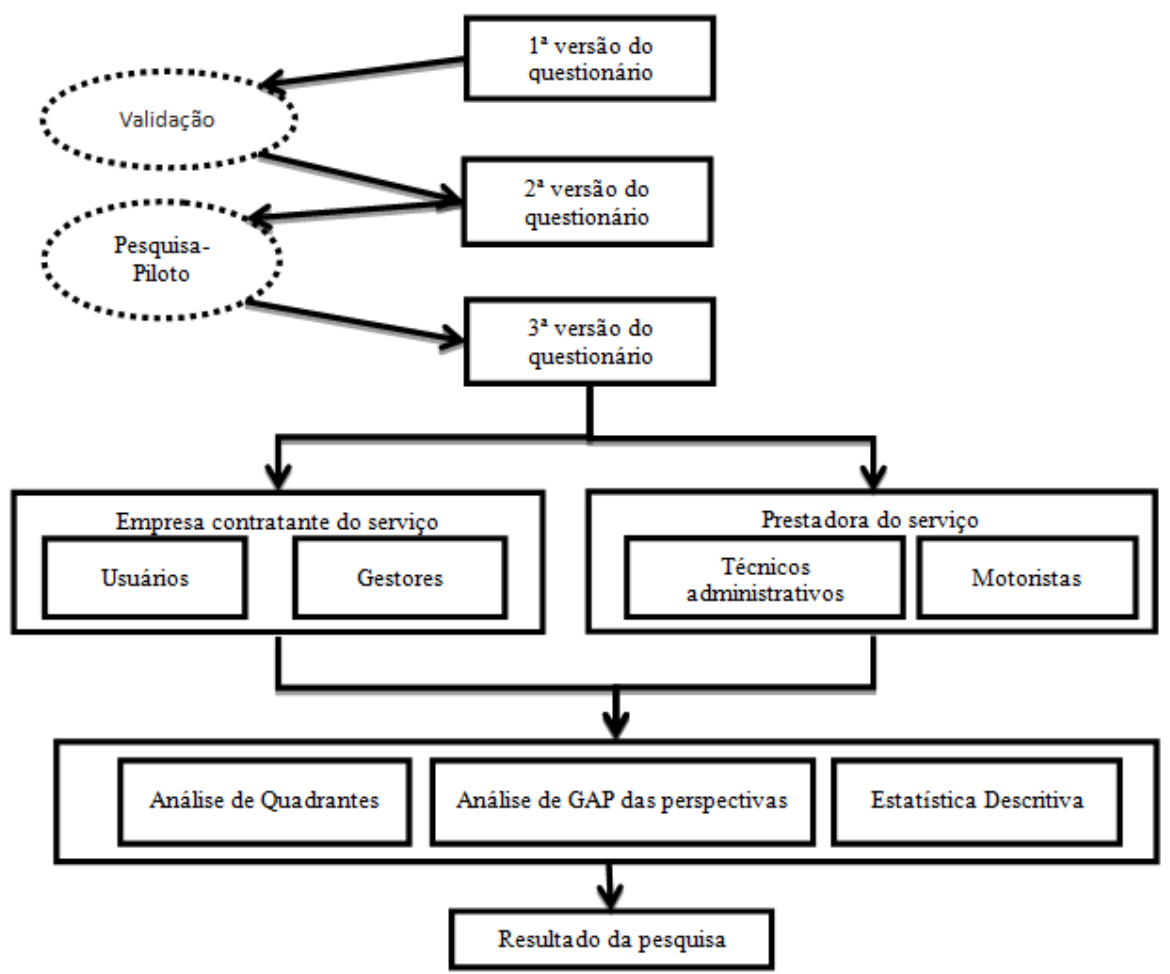

Fonte: Elaborado pelos autores

A partir da construção da primeira versão do questionário, deve-se validá-lo por meio de uma reunião com os responsáveis da empresa contratante, cujas sugestões resultam na 2 a versão do questionário a ser validada em uma pesquisapiloto que deve ser aplicada em um conjunto pequeno de usuários do transporte bem como com alguns motoristas. Pretende-se com essa pesquisa-piloto realizar possíveis ajustes no questionário, além de verificar a existência de outras características e, até mesmo, verificar se a redação do questionário atende ao nível de linguagem do público. Com base nesses resultados, questionários podem 
ser desenvolvidos para os grupos menores: equipe de transporte da empresa contratante responsável pela gestão do contrato e equipe operacional da prestadora do serviço. O resultado dessa fase gera as versões finais dos questionários (para os usuários, os motoristas, a equipe de transporte da EC e a equipe operacional da PS).

As versões finais dos questionários devem ser aplicadas aos quatro atores envolvidos na pesquisa (usuários, motoristas, gestores do contrato e equipe administrativa da prestadora do serviço), segundo a metodologia a seguir:

10 Passo - Aplicação do Questionário aos Usuários: a fim de facilitar a aplicação do questionário aos usuários, a sua versão final foi apresentada na plataforma WEB (Formulários Google) e o seu link de acesso enviado via e-mail a cada um dos passageiros do transporte fretado da Empresa Contratante.

2ㅇ Passo - Aplicação do Questionário aos Motoristas: o método da aplicação do questionário, entrevistas pessoais e individuais ou preenchimento via WEB, deve ser definido em conjunto com a Empresa Contratante, pois deve ser verificado se os motoristas possuem acesso remoto à internet e instrução adequada para o correto preenchimento do questionário.

3o Passo - Aplicação do Questionário à Prestadora do Serviço e à Contratante: como o número de funcionários envolvidos na gestão do contrato de transporte entre a EC e a PS é pequeno, foram realizadas entrevistas pessoais e individuais com cada entrevistado, com o intuito de preencher o questionário estruturado. A definição por essas entrevistas, nesse caso, se deve ao fato de que o público-alvo encontra-se numa área geográfica restrita, o local de trabalho dos gestores do contrato na EC e a sala de trabalho dos profissionais dedicados a esse contrato na empresa PS, além de que permite o registro de informações adicionais que poderão ser importantes para a pesquisa.

Quanto à determinação do tamanho da amostra, deve-se definir qual a margem de incerteza aceitável para a pesquisa e, para isso, necessita-se especificar o nível de confiança e o erro amostral (OLIVEIRA, 2006). O nível de confiança é uma medida estatística que indica a probabilidade de repetição dos resultados obtidos caso seja efetuada novamente a mesma pesquisa. A margem de erro identifica a variação dos resultados de uma pesquisa. Um erro amostral de $5 \%$ indica que os percentuais de respostas obtidas podem variar para mais $5 \%$ ou menos 5\% (GOMES, 2005). Ou seja, representa o nível de precisão alcançado na amostragem. Rea e Parker (2000) afirmam que os valores mais usados são 95\% e $99 \%$ para o nível de confiança e de 3 a $5 \%$ para o erro amostral. Para o grupo dos usuários e motoristas, foram calculadas as amostras estatísticas a partir da aplicação da Equação 1 (Rea e Parker, 2000), que atenda ao intervalo de confiança de $95 \%$ e erro admissível de $5 \%$.

$$
n=\frac{Z^{2} \cdot p \cdot q \cdot N}{d^{2}(N-1)+Z^{2} \cdot p \cdot q}
$$

Em que: $n=$ amostra estatística; $\mathrm{Z}=1,96$ (equivalente a um intervalo de confiança de 95\%); $p=0,5$ (estimativa da proporção); $q=1-p ; N=$ tamanho da população; $d=5 \%$ (erro amostral, expresso em decimais).

Os dados coletados foram tabulados em quatro planilhas eletrônicas: usuários, motoristas, equipe administrativa da empresa contratante e equipe administrativa da prestadora do serviço. Ao tabular os dados, as respostas que 
tinham mais de uma entrada foram consideradas inválidas, bem como as entradas em branco.

A Figura 4 ilustra as diversas lacunas (diferenças de percepções) que podem existir na mensuração da qualidade entre os agentes, tais como, entre a empresa e a operadora, entre a operadora e o usuário, entre a empresa e o usuário, além do GAP de qualidade entre um agente e ele próprio. Destaca-se também a lacuna de percepção que pode existir entre a empresa (incluindo os usuários) e a operadora do serviço.

Figura 4 - Interações entre os Agentes

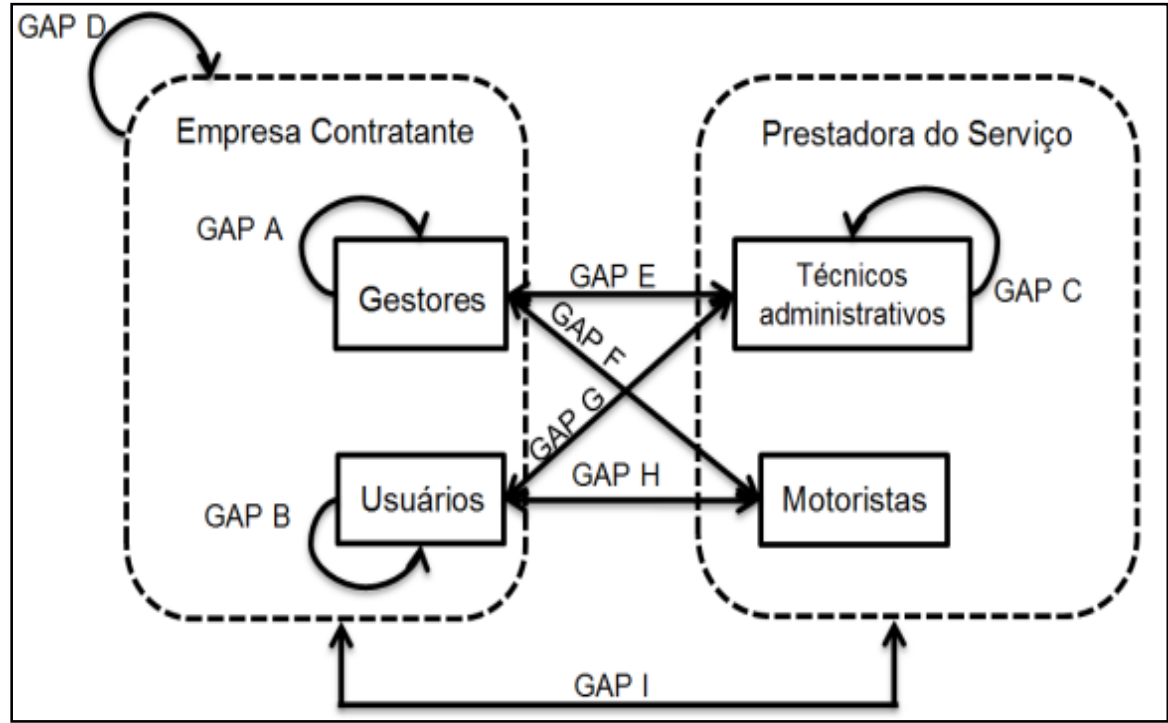

Fonte: Elaborado pelos autores

Os GAPs ilustrados possibilitam identificar os principais problemas relativos ao transporte fretado de funcionários por ônibus pela visão dos diferentes atores envolvidos. Em resumo, nas definições abaixo, representam a diferença entre a expectativa sobre o serviço:

- GAP A: ... e a percepção sobre o serviço prestado na visão dos gestores de transporte da empresa contratante.

- GAP B: ... e a percepção sobre o serviço prestado na visão dos usuários.

- GAP C: ... e a percepção sobre o serviço prestado na visão dos técnicos administrativos da prestadora do serviço.

- GAP D: ... e a percepção sobre o serviço prestado na visão da empresa contratante.

- GAP E: ... na visão dos gestores de transporte da empresa contratante e da percepção dos técnicos administrativos da prestadora do serviço.

- GAP F: ... na visão dos gestores de transporte da empresa contratante e a percepção sobre o serviço na visão dos motoristas da prestadora do serviço.

- GAP G: ... na visão dos usuários e a percepção sobre o serviço na visão dos técnicos administrativos da prestadora do serviço.

- GAP H: ... na visão dos usuários e a percepção sobre o serviço na visão dos motoristas. 
- GAP I: ... na visão da empresa contratante (gestores e usuários) e a percepção sobre o serviço na visão da prestadora do serviço (técnicos administrativos e motoristas).

Os GAPs A, B e C foram inspirados no GAP 5 do modelo de medição da qualidade publicado por Parassuram et al. (1988). Já os GAPs D, E, F, G, H e I são adaptações do GAP 1 desse mesmo modelo e consiste na distância existente entre a percepção que os fornecedores têm a respeito das expectativas dos clientes e as expectativas dos clientes propriamente ditas. A identificação destas lacunas tem a função de ajudar as empresas a evidenciarem características onde há potencial oportunidade de desinvestimento (expectativa do cliente superestimada), ou investimento (expectativa do cliente subestimada).

\section{ANÁLISE DOS RESULTADOS}

O GAP é calculado a partir da diferença entre as médias das percepções de determinada característica e a percepção desta expectativa. Valores de GAP positivo são as oportunidades de desinvestimento; negativo, as oportunidades de investimento. Como exemplo, serão apresentados os cálculos dos GAPs B e D, por serem referentes ao GAP 5, que é a variável que mensura a qualidade do serviço, definido por Parasuraman et al. (1985), e o GAP G, por corresponder ao GAP 1, que apresenta a lacuna entre as expectativas dos usuários e as percepções do provedor do serviço.

\section{GAP B}

Para o cálculo do GAP B é necessário a realização do teste t-Student, que identifica a diferença entre médias de duas populações, a partir de amostras retiradas aos pares.

Para o Teste de Hipóteses:

H0: $(\mu \mathrm{P}-\mu \mathrm{E})=0$ => Inexistência do GAP

Ha: $(\mu \mathrm{P}-\mu \mathrm{E})>0$ ou $(\mu \mathrm{P}-\mu \mathrm{E})<0=>\mathrm{GAP}$

Foi utilizada a Equação 2:

$$
t=\frac{(P-E)}{S_{(P-E)} * \sqrt{n}}
$$

Onde: $\mathrm{P}=$ percepção; $\mathrm{E}=$ expectativa; $\mathrm{S}=$ desvio-padrão; $\mathrm{n}=$ número da amostra.

A Tabela 1 contém a identificação e quantificação da diferença entre percepção e expectativa do serviço prestado na visão dos usuários para as 24 características da qualidade do serviço de transporte fretado. Como o nível de significância utilizado é de $95 \%$ (portanto $\alpha=0,05$ ), considera-se que há evidências suficientes a um nível de significância de $95 \%$ para rejeitar a hipótese nula em favor da existência de um GAP, sempre que o $p$-value encontrado for inferior a 0,05. 
Tabela 1 - Medição do GAP B (usuários)

\begin{tabular}{|c|c|c|c|c|c|}
\hline Característica & $\mathrm{T}$ & GI & P-VALUE & GAB & OK? \\
\hline $\begin{array}{l}\text { 1. Proximidade do ponto de ônibus até } \\
\text { a sua casa }\end{array}$ & 0,102 & 448 & 0,918 & 0,006 & $\mathrm{~N}$ \\
\hline $\begin{array}{l}\text { 2. Configuração da rede dos pontos de } \\
\text { ônibus do seu trajeto (localização, } \\
\text { quantidade e distância entre os } \\
\text { pontos) }\end{array}$ & $-3,149$ & 451 & 0,001 & $-0,176$ & S \\
\hline 3. Tempo de viagem & $-13,461$ & 449 & 0,000 & $-0,922$ & $S$ \\
\hline $\begin{array}{l}\text { 4. Respeito à capacidade de lotação do } \\
\text { ônibus }\end{array}$ & $-9,666$ & 448 & 0,000 & $-0,494$ & $S$ \\
\hline 5. Pontualidade (respeito aos horários) & $-7,494$ & 447 & 0,000 & $-0,339$ & s \\
\hline $\begin{array}{l}\text { 6. Segurança em andar nos ônibus com } \\
\text { relação a acidentes }\end{array}$ & $-7,474$ & 448 & 0,000 & $-0,204$ & s \\
\hline 7. Segurança com relação a assaltos & $-8,496$ & 444 & 0,000 & $-0,319$ & s \\
\hline 8. Limpeza dentro dos veículos & $-5,757$ & 446 & 0,000 & $-0,214$ & S \\
\hline 9. Estado de conservação do veículo & $-0,845$ & 446 & 0,398 & $-0,024$ & $\mathrm{~N}$ \\
\hline 10. Conforto das cadeiras & $-6,074$ & 446 & 0,000 & $-0,259$ & $\mathrm{~s}$ \\
\hline 11. Temperatura interna do veículo & 1,055 & 446 & 0,291 & 0,035 & $\mathrm{~N}$ \\
\hline $\begin{array}{l}\text { 12. Espaço no ônibus para a } \\
\text { movimentação dos passageiros }\end{array}$ & $-3,239$ & 447 & 0,001 & $-0,151$ & S \\
\hline $\begin{array}{l}\text { 13. Espaço para bagagens dos } \\
\text { passageiros }\end{array}$ & 12,733 & 436 & 0,000 & 0,805 & $\mathrm{~s}$ \\
\hline $\begin{array}{l}\text { 14. Facilidade de subida e descida do } \\
\text { veículo }\end{array}$ & 3,218 & 446 & 0,001 & 0,131 & S \\
\hline $\begin{array}{l}\text { 15. Dispositivos de segurança } \\
\text { adequados ao uso (cinto de segurança, } \\
\text { extintor de incêndio, saída de } \\
\text { emergência, etc) }\end{array}$ & $-5,145$ & 443 & 0,000 & $-0,132$ & S \\
\hline $\begin{array}{l}\text { 16. Informações existentes nos veículos } \\
\text { (alteração de itinerário e avisos } \\
\text { diversos) }\end{array}$ & $-9,023$ & 446 & 0,000 & $-0,436$ & S \\
\hline $\begin{array}{l}\text { 17. Ter canais de comunicação para o } \\
\text { passageiro elogiar, reclamar e sugerir }\end{array}$ & $-14,470$ & 442 & 0,000 & $-0,930$ & $S$ \\
\hline $\begin{array}{l}\text { 18. Rapidez para trocar de ônibus } \\
\text { dentro da empresa }\end{array}$ & $-9,726$ & 442 & 0,000 & $-0,510$ & S \\
\hline $\begin{array}{l}\text { 19. Infraestrutura da rodoviária interna } \\
\text { à empresa }\end{array}$ & $-8,277$ & 445 & 0,000 & $-0,428$ & $\mathrm{~s}$ \\
\hline $\begin{array}{l}\text { 20. Educação do motorista com os } \\
\text { passageiros }\end{array}$ & $-4,053$ & 445 & 0,059 & $-0,139$ & S \\
\hline $\begin{array}{l}\text { 21. Segurança passada pelos } \\
\text { motoristas ao dirigir }\end{array}$ & $-11,778$ & 445 & 0,000 & $-0,423$ & S \\
\hline $\begin{array}{l}\text { 22. Possibilidade de alteração do } \\
\text { itinerário }\end{array}$ & $-5,192$ & 437 & 0,000 & $-0,319$ & S \\
\hline 23. Campainha do ônibus & 5,941 & 435 & 0,000 & 0,316 & $S$ \\
\hline $\begin{array}{l}\text { 24. Rapidez na solução de problemas } \\
\text { com o ônibus na rua }\end{array}$ & $-10,538$ & 437 & 0,000 & $-0,488$ & $\mathrm{~s}$ \\
\hline $\begin{array}{l}\text { 21. Segurança passada pelos } \\
\text { motoristas ao dirigir }\end{array}$ & $-11,778$ & 445 & 0,000 & $-0,423$ & S \\
\hline $\begin{array}{l}\text { 22. Possibilidade de alteração do } \\
\text { itinerário }\end{array}$ & $-5,192$ & 437 & 0,000 & $-0,319$ & S \\
\hline 23. Campainha do ônibus & 5,941 & 435 & 0,000 & 0,316 & $\mathrm{~s}$ \\
\hline $\begin{array}{l}\text { 24. Rapidez na solução de problemas } \\
\text { com o ônibus na rua }\end{array}$ & $-10,538$ & 437 & 0,000 & $-0,488$ & S \\
\hline
\end{tabular}

Os resultados da Tabela 1 sugerem que somente nas características Proximidade do ponto de ônibus até a sua casa (1), Estado de conservação do veículo (9) e Temperatura interna do veículo (11) não há diferenças entre as expectativas e percepções dos usuários, ou seja, a não existência de um GAP. 
Dentre os três GAPs positivos, pode-se destacar o da característica Espaço para bagagens dos passageiros (13), visto que os funcionários ao irem para empresa não demandam tanta bagagem, necessitando de no máximo bolsa ou mochila para o seu dia de trabalho. Já o GAP positivo existente na característica Facilidade de subida e descida do veículo (14) pode ser explicado devido à existência de um dispositivo existente nos ônibus, um degrau fixo a mais para facilitar a subida e descida dos passageiros. E por último, o GAP positivo da característica Campainha do ônibus (23) pode ser explicado devido a troca de toda a frota ocorrida no início do ano que resultou em ônibus $0 \mathrm{~km}$.

Por outro lado, os resultados sugerem a concentração dos esforços em solucionar os GAPs negativos existentes nas características Tempo de viagem (3), Ter canais de comunicação para o passageiro elogiar, reclamar e sugerir (17) e Rapidez para trocar de ônibus dentro da empresa (18). Em entrevistas com as equipes de transporte da empresa contratante e a prestadora do serviço, verificou-se o consenso de que para a redução do tempo de viagem as restrições externas à empresa superam as internas, tais como o trânsito das cidades circunvizinhas à empresa focal deste estudo, o que torna a solução desta característica bastante complexa. Isto difere do potencial de solução da característica Ter canais de comunicação para o passageiro elogiar, reclamar e sugerir (17), que depende exclusivamente das empresas envolvidas neste estudo e que não demanda tanto investimento financeiro, portanto muito mais fácil de ser resolvido. Por fim, a característica Rapidez para trocar de ônibus dentro da empresa (18) necessita de estudos mais aprofundados para ser solucionado.

\section{GAP D}

O GAP D representa a diferença entre a expectativa sobre o serviço e a percepção sobre o serviço prestado na visão da empresa contratante (EC), que inclui a visão da equipe de gestores de transporte e os usuários do transporte fretado. Assim, para o cálculo da percepção sobre o serviço pela empresa contratante, calculou-se a média da percepção dos gestores e usuários. Da mesma forma, pôde-se calcular a média da percepção sobre o serviço prestado na visão da empresa contratante, calculando-se a média da percepção dos gestores e usuários. Subtraindo-se esses dois valores (média da percepção e média da expectativa) pôde-se calcular ao GAP D, que é apresentado na Tabela 2. 
Tabela 2 - Medição do GAP D (gestores e usuários da empresa contratante)

\begin{tabular}{|c|c|c|c|}
\hline Característica & $\begin{array}{c}\text { Média das } \\
\text { Percepções da } \\
\text { EC }\end{array}$ & $\begin{array}{c}\text { Média das } \\
\text { Expectativa } \\
\text { s da EC }\end{array}$ & GAP D \\
\hline 1. Proximidade do ponto de ônibus até a sua casa & 4,5860 & 4,0845 & 0,5015 \\
\hline $\begin{array}{l}\text { 2. Configuração da rede dos pontos de ônibus do } \\
\text { seu trajeto (localização, quantidade e distância } \\
\text { entre os pontos) }\end{array}$ & 4,1725 & 4,0110 & 0,1615 \\
\hline 3. Tempo de viagem & 4,0760 & 4,7880 & $-0,7102$ \\
\hline 4. Respeito à capacidade de lotação do ônibus & 4,0855 & 4,8320 & $-0,7465$ \\
\hline 5. Pontualidade (respeito aos horários) & 4,6905 & 4,8590 & $-0,1685$ \\
\hline $\begin{array}{l}\text { 6. Segurança em andar nos ônibus com relação a } \\
\text { acidentes }\end{array}$ & 4,8385 & 4,9415 & $-0,1030$ \\
\hline 7. Segurança com relação a assaltos & 4,6340 & 4,7935 & $-0,1595$ \\
\hline 8. Limpeza dentro dos veículos & 4,6180 & 4,8495 & $-0,2315$ \\
\hline 9. Estado de conservação do veículo & 4,8760 & 4,8880 & $-0,0120$ \\
\hline 10. Conforto das cadeiras & 4,6900 & 4,6955 & $-0,0055$ \\
\hline 11. Temperatura interna do veículo & 4,7090 & 4,5680 & 0,1410 \\
\hline $\begin{array}{l}\text { 12. Espaço no ônibus para a movimentação dos } \\
\text { passageiros }\end{array}$ & 4,5515 & 4,3015 & 0,2500 \\
\hline 13. Espaço para bagagens dos passageiros & 4,1275 & 3,2525 & 0,8750 \\
\hline 14. Facilidade de subida e descida do veículo & 4,6920 & 4,6920 & 0,0000 \\
\hline $\begin{array}{l}\text { 15. Dispositivos de segurança adequados ao uso } \\
\text { (cinto de segurança, extintor de incêndio, saída de } \\
\text { emergência, etc) }\end{array}$ & 4,7995 & 4,9245 & $-0,1250$ \\
\hline $\begin{array}{l}\text { 16. Informações existentes nos veículos (alteração } \\
\text { de itinerário e avisos diversos) }\end{array}$ & 4,7880 & 4,7880 & 0,0000 \\
\hline $\begin{array}{l}\text { 17. Ter canais de comunicação para o passageiro } \\
\text { elogiar, reclamar e sugerir }\end{array}$ & 4,6800 & 4,0550 & 0,6250 \\
\hline $\begin{array}{l}\text { 18. Rapidez para trocar de ônibus dentro da } \\
\text { empresa }\end{array}$ & 4,5835 & 4,7085 & $-0,1250$ \\
\hline 19. Infraestrutura da rodoviária interna à empresa & 4,7045 & 4,7045 & 0,0000 \\
\hline 20. Educação do motorista com os passageiros & 4,7040 & 4,8290 & $-0,1250$ \\
\hline 21. Segurança passada pelos motoristas ao dirigir & 4,7775 & 4,9025 & $-0,1250$ \\
\hline 22. Possibilidade de alteração do itinerário & 4,4805 & 4,3555 & 0,1250 \\
\hline 23. Campainha do ônibus & 4,3830 & 4,5080 & $-0,1250$ \\
\hline $\begin{array}{l}\text { 24. Rapidez na solução de problemas com o ônibus } \\
\text { na rua }\end{array}$ & 4,5385 & 4,7885 & $-0,2500$ \\
\hline
\end{tabular}

Os resultados da Tabela 2 sugerem que na visão da empresa contratante somente três características não apresentam GAP da qualidade $(G A P=0,0000)$. Pode-se detectar a presença de dois GAPs negativos: Tempo de viagem (3) e Respeito à capacidade de lotação do veículo (4). Dentre os quatorze GAPs negativos, ressalta-se que a existência de GAP na característica Tempo de viagem (GAP D $=-0,712$ ) era esperada, visto que os horários de entrada e saída da empresa são os horários de maior movimento na região da Grande Vitória, onde o tempo de viagem é em média de 60 minutos, chegando por vezes a ser de 1 hora e meia. Já a característica Respeito à capacidade de lotação do veículo (4), que obteve o maior GAP negativo (GAP D $=-0,7465)$ pode ser explicada visto que por vezes colaboradores são transportados em pé. 
Dentre os seis GAPs positivos, cabe observar que já era esperada a excelente avaliação da característica Espaço para bagagens dos passageiros (GAP D = $0,875)$, por se tratar de um transporte de funcionários, que não necessitam levar junto a si tantas bagagens para o trabalho. Ainda, a característica Ter canais de comunicação para o passageiro elogiar, reclamar e sugerir (17), que obteve a segunda melhor avaliação (GAP D =0,625), pode ser explicada pelo fato da equipe que gerencia o contrato do serviço de transporte manter telefones disponíveis para quaisquer necessidades, além de possibilitar contatos por emails. Por fim, a boa avaliação da característica Proximidade do ponto de ônibus até a sua casa (GAP D $=0,5015$ ) também era esperada, visto que os locais utilizados para embarque e desembarque internos e externos são definidos onde houver pontos devidamente demarcados ou sinalizados pelos órgãos competentes, o que garante satisfatoriamente o atendimento desse quesito.

\section{GAP G}

Através da Tabela 3, pode-se visualizar o GAP G.

Tabela 3. Medição do GAP G.

\begin{tabular}{|c|c|c|c|}
\hline Característica & $\begin{array}{l}\text { Média da } \\
\text { Percepção dos } \\
\text { Tec Adm }\end{array}$ & $\begin{array}{l}\text { Média da } \\
\text { Expectativa } \\
\text { dos } \\
\text { Usuários }\end{array}$ & GAP D \\
\hline $\begin{array}{l}\text { 1. Proximidade do ponto de ônibus até a } \\
\text { sua casa }\end{array}$ & 4,000 & 4,419 & $-0,419$ \\
\hline $\begin{array}{l}\text { 2. Configuração da rede dos pontos de ônibus do } \\
\text { seu trajeto (localização, quantidade e distância } \\
\text { entre os pontos) }\end{array}$ & 4,000 & 4,272 & $-0,272$ \\
\hline 3. Tempo de viagem & 4,400 & 4,576 & $-0,176$ \\
\hline $\begin{array}{l}\text { 4. Respeito à capacidade de lotação do } \\
\text { ônibus }\end{array}$ & 4,400 & 4,664 & $-0,264$ \\
\hline 5. Pontualidade (respeito aos horários) & 4,600 & 4,718 & $-0,118$ \\
\hline $\begin{array}{l}\text { 6. Segurança em andar nos ônibus com } \\
\text { relação a acidentes }\end{array}$ & 5,000 & 4,883 & 0,117 \\
\hline 7. Segurança com relação a assaltos & 4,800 & 4,837 & $-0,037$ \\
\hline 8. Limpeza dentro dos veículos & 4,600 & 4,699 & $-0,099$ \\
\hline 9. Estado de conservação do veículo & 5,000 & 4,776 & 0,224 \\
\hline 10. Conforto das cadeiras & 4,800 & 4,641 & 0,159 \\
\hline 11. Temperatura interna do veículo & 4,800 & 4,636 & 0,164 \\
\hline $\begin{array}{l}\text { 12. Espaço no ônibus para a movimentação } \\
\text { dos passageiros }\end{array}$ & 4,600 & 4,353 & 0,247 \\
\hline 13. Espaço para bagagens dos passageiros & 4,600 & 3,505 & 1,095 \\
\hline $\begin{array}{l}\text { 14. Facilidade de subida e descida do } \\
\text { veículo }\end{array}$ & 5,000 & 4,384 & 0,616 \\
\hline $\begin{array}{l}\text { 15. Dispositivos de segurança adequados ao uso } \\
\text { (cinto de segurança, extintor de incêndio, saída de } \\
\text { emergência, etc) }\end{array}$ & 5,000 & 4,849 & 0,151 \\
\hline $\begin{array}{l}\text { 16. Informações existentes nos veículos } \\
\text { (alteração de itinerário e avisos diversos) }\end{array}$ & 4,800 & 4,576 & 0,224 \\
\hline $\begin{array}{l}\text { 17. Ter canais de comunicação para o } \\
\text { passageiro elogiar, reclamar e sugerir }\end{array}$ & 4,600 & 4,360 & 0,240 \\
\hline $\begin{array}{l}\text { 18. Rapidez para trocar de ônibus dentro da } \\
\text { empresa }\end{array}$ & 4,600 & 4,417 & 0,183 \\
\hline
\end{tabular}




\begin{tabular}{|c|c|c|c|}
\hline Característica & $\begin{array}{l}\text { Média da } \\
\text { Percepção dos } \\
\text { Tec Adm }\end{array}$ & $\begin{array}{c}\text { Média da } \\
\text { Expectativa } \\
\text { dos } \\
\text { Usuários }\end{array}$ & GAP D \\
\hline $\begin{array}{l}\text { 19. Infraestrutura da rodoviária interna à } \\
\text { empresa }\end{array}$ & 4,800 & 4,409 & 0,391 \\
\hline $\begin{array}{l}\text { 20. Educação do motorista com os } \\
\text { passageiros }\end{array}$ & 5,000 & 4,658 & 0,342 \\
\hline $\begin{array}{l}\text { 21. Segurança passada pelos motoristas ao } \\
\text { dirigir }\end{array}$ & 5,000 & 4,805 & 0,195 \\
\hline 22. Possibilidade de alteração do itinerário & 4,800 & 4,211 & 0,589 \\
\hline 23. Campainha do ônibus & 4,600 & 4,016 & 0,584 \\
\hline $\begin{array}{l}\text { 24. Rapidez na solução de problemas com o } \\
\text { ônibus na rua }\end{array}$ & 4,800 & 4,577 & 0,223 \\
\hline
\end{tabular}

O resultado obtido através da Tabela 3 sugere que os técnicos administrativos da prestadora do serviço têm uma percepção muito precisa das expectativas dos usuários. Contudo, é evidente a percepção dos técnicos de que, em sua maioria, as características são atendidas a mais do que o mínimo exigido, ou seja, podem sofrer desinvestimento, tais como as características 13, 14, 22 e 23. Porém, esta tabela indica características que precisam de investimentos tais como a 1 e a 2, o que confirma a mesma análise feita para a característica Tempo de Viagem (3). Esta medição também pode sofrer influência de utilizações pessoais da escala ( 1 a 5), pois os respondentes em cada um dos eixos são distintos.

Na Tabela 4, que apresenta uma visão geral de todos os GAPs analisados, as células assinaladas com NA indicam GAPs não avaliados ou calculados (citar os possíveis motivos; as sombreadas em cinza claro contêm os GAPs positivos, que indicam que a discrepância entre a percepção e a expectativa sobre o serviço é maior que zero, ou seja, a percepção da qualidade é maior do que a esperada; já as células sombreadas em cinza escuro contêm características que não foram bem avaliadas, que necessitam de investimento, ou seja, a qualidade percebida é menor do que a qualidade esperada. Percebe-se que a característica Respeito à capacidade de lotação do ônibus (4) obteve por unanimidade uma avaliação ruim quanto à sua qualidade. Por outro lado, a característica Espaço para bagagens dos passageiros (13), por unanimidade, foi muito bem avaliada.

Tabela 4 - Visão geral das Medições dos GAPs

\begin{tabular}{|c|c|c|c|c|c|c|c|c|c|}
\hline Característica & & $\begin{array}{l}\text { GAP } \\
\text { A }\end{array}$ & $\begin{array}{c}\text { GAP } \\
\text { B }\end{array}$ & $\begin{array}{c}\text { GAP } \\
\text { C }\end{array}$ & $\begin{array}{c}\text { GAP } \\
\text { D }\end{array}$ & $\begin{array}{l}\text { GAP } \\
\text { E }\end{array}$ & $\begin{array}{c}\text { GAP } \\
\text { G }\end{array}$ & GAP & $\begin{array}{c}\text { GAP } \\
\text { H }\end{array}$ \\
\hline $\begin{array}{l}\text { 1. Proximidade do ponto } \\
\text { de ônibus até a sua casa }\end{array}$ & 1,000 & 0,000 & 0,000 & 0,501 & 0,250 & NA & $-0,419$ & NA & $\begin{array}{c}- \\
0,084 \\
\end{array}$ \\
\hline $\begin{array}{l}\text { 2. Configuração da rede dos } \\
\text { pontos de ônibus do seu trajeto } \\
\text { (localização, quantidade e } \\
\text { distância entre os pontos) }\end{array}$ & 0,500 & $-0,176$ & 0,000 & 0,161 & 0,250 & NA & $-0,272$ & NA & - \\
\hline 3. Tempo de viagem & $-0,500$ & $-0,922$ & 0,400 & $-0,712$ & $-0,600$ & $-0,792$ & $-0,176$ & $-0,368$ & $\stackrel{-}{0,484}$ \\
\hline $\begin{array}{l}\text { 4. Respeito à capacidade } \\
\text { de lotação do ônibus }\end{array}$ & $-1,000$ & $-0,494$ & $-0,400$ & $-0,746$ & $-0,600$ & $-0,918$ & $-0,264$ & $-0,582$ & $\begin{array}{c}- \\
0,591\end{array}$ \\
\hline $\begin{array}{l}\text { 5. Pontualidade (respeito } \\
\text { aos horários) }\end{array}$ & 0,000 & $-0,339$ & $-0,200$ & $-0,168$ & $-0,400$ & $-0,694$ & $-0,118$ & $-0,412$ & $\begin{array}{c}- \\
0,406\end{array}$ \\
\hline $\begin{array}{l}\text { 6. Segurança em andar nos } \\
\text { ônibus com relação a } \\
\text { acidentes }\end{array}$ & 0,000 & $-0,205$ & 0,000 & $-0,103$ & 0,000 & $-0,482$ & 0,117 & $-0,365$ & 0,182 \\
\hline 7. Segurança com relação a & 0,000 & $-0,319$ & 0,000 & $-0,159$ & 0,050 & $-0,386$ & $-0,037$ & $-0,473$ & - \\
\hline
\end{tabular}




\begin{tabular}{|c|c|c|c|c|c|c|c|c|c|}
\hline \multicolumn{2}{|l|}{ Característica } & GAP & GAP & GAP & GAP & GAP & GAP & GAP & $\begin{array}{c}\text { GAP } \\
\mathrm{H}\end{array}$ \\
\hline assaltos & & & & & & & & & 0,211 \\
\hline $\begin{array}{l}\text { 8. Limpeza dentro dos } \\
\text { veículos }\end{array}$ & $-0,250$ & $-0,215$ & $-0,200$ & $-0,231$ & $-0,400$ & $-1,230$ & $-0,099$ & $-0,929$ & $\begin{array}{c}- \\
0,664 \\
\end{array}$ \\
\hline $\begin{array}{l}\text { 9. Estado de conservação } \\
\text { do veículo }\end{array}$ & 0,000 & 0,000 & 0,200 & $-0,012$ & 0,000 & $-0,566$ & 0,224 & $-0,342$ & $\begin{array}{c}- \\
0,171 \\
\end{array}$ \\
\hline 10. Conforto das cadeiras & 0,250 & $-0,259$ & 0,000 & $-0,005$ & 0,050 & $-0,431$ & 0,159 & $-0,322$ & $\begin{array}{c}- \\
0,136\end{array}$ \\
\hline $\begin{array}{l}\text { 11. Temperatura interna } \\
\text { do veículo }\end{array}$ & 0,250 & 0,000 & 0,200 & 0,141 & 0,300 & $-0,587$ & 0,164 & $-0,723$ & 0,211 \\
\hline $\begin{array}{l}\text { 12. Espaço no ônibus para a } \\
\text { movimentação dos } \\
\text { passageiros }\end{array}$ & 0,500 & $-0,152$ & 0,200 & 0,250 & 0,350 & $-0,126$ & 0,247 & $-0,229$ & 0,060 \\
\hline $\begin{array}{l}\text { 13. Espaço para bagagens } \\
\text { dos passageiros }\end{array}$ & 1,750 & 0,805 & 0,800 & 0,875 & 1,600 & 1,274 & 1,095 & 0,769 & 1,184 \\
\hline $\begin{array}{l}\text { 14. Facilidade de subida e } \\
\text { descida do veículo }\end{array}$ & 0,000 & 0,132 & 0,200 & 0,000 & 0,000 & $-0,570$ & 0,616 & 0,046 & 0,023 \\
\hline $\begin{array}{l}\text { 15. Dispositivos de segurança } \\
\text { adequados ao uso (cinto de } \\
\text { segurança, extintor de incêndio, } \\
\text { saída de emergência, etc) }\end{array}$ & $-0,250$ & $-0,133$ & 0,000 & $-0,125$ & 0,000 & $-0,487$ & 0,151 & $-0,336$ & $\overline{-}, 168$ \\
\hline $\begin{array}{l}\text { 16. Informações existentes } \\
\text { nos veículos (alteração de } \\
\text { itinerário e avisos diversos) }\end{array}$ & 0,000 & $-0,436$ & 0,000 & 0,000 & $-0,200$ & $-0,894$ & 0,224 & $-0,470$ & 0,335 \\
\hline $\begin{array}{lrr}17 . \quad \text { Ter } & \text { canais } & \text { de } \\
\text { comunicação } & \text { para } & \text { o } \\
\text { passageiro } & \text { elogiar, } \\
\text { reclamar e sugerir } & \\
\end{array}$ & 1,250 & $-0,930$ & 0,000 & 0,625 & 0,850 & NA & 0,240 & NA & 0,545 \\
\hline $\begin{array}{l}\text { 18. Rapidez para trocar de } \\
\text { ônibus dentro da empresa }\end{array}$ & $-0,250$ & $-0,510$ & 0,400 & $-0,125$ & $-0,400$ & $-1,088$ & 0,183 & $-0,505$ & $\begin{array}{c}- \\
0,452 \\
\end{array}$ \\
\hline $\begin{array}{lrr}19 . \quad \text { Infraestrutura } & \text { da } \\
\text { rodoviária interna } & \text { à } \\
\text { empresa } & & \\
\end{array}$ & 0,000 & $-0,428$ & $-0,200$ & 0,000 & $-0,200$ & $-1,149$ & 0,391 & $-0,558$ & $\begin{array}{c}- \\
0,379\end{array}$ \\
\hline $\begin{array}{l}\text { 20. Educação do motorista } \\
\text { com os passageiros }\end{array}$ & $-0,250$ & $-0,139$ & 0,000 & $-0,125$ & 0,000 & NA & 0,342 & NA & 0,171 \\
\hline $\begin{array}{l}\text { 21. Segurança passada } \\
\text { pelos motoristas ao dirigir }\end{array}$ & $-0,250$ & $-0,424$ & 0,000 & $-0,125$ & 0,000 & NA & 0,195 & NA & 0,097 \\
\hline $\begin{array}{lcc}22 . & \text { Possibilidade } & \text { de } \\
\text { alteração do itinerário } & \end{array}$ & 0,250 & $-0,320$ & 0,600 & 0,125 & 0,300 & NA & 0,589 & NA & 0,444 \\
\hline 23. Campainha do ônibus & $-0,250$ & 0,316 & 0,200 & $-0,125$ & $-0,400$ & $-0,617$ & 0,584 & 0,367 & 0,016 \\
\hline $\begin{array}{l}\text { 24. Rapidez na solução de } \\
\text { problemas com o ônibus na } \\
\text { rua }\end{array}$ & $-0,500$ & $-0,488$ & $-0,200$ & $-0,25$ & $-0,200$ & NA & 0,223 & NA & 0,011 \\
\hline
\end{tabular}

A partir da Tabela 4, pode-se criar a Tabela 5, que ressalta as características que possuem maiores GAPs positivos e negativos, levando-se em conta as diversas visões.

Tabela 5 - Tabela Conclusão

\section{Característica}

\section{GAP GAP GAP GAP GAP GAP GAP GAP GAP}

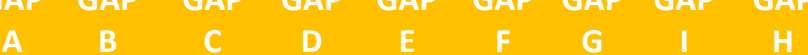

\begin{tabular}{l}
\hline 1. Proximidade do ponto de ônibus até a sua casa \\
2. Configuração da rede dos pontos de ônibus do seu trajeto \\
(localização, quantidade e distância entre os pontos) \\
\hline 3. Tempo de viagem \\
\hline 4. Respeito à capacidade de lotação do ônibus \\
\hline 5. Pontualidade (respeito aos horários) \\
\hline 6. Segurança em andar nos ônibus com relação a acidentes \\
\hline 7. Segurança com relação a assaltos \\
\hline 8. Limpeza dentro dos veículos \\
\hline 9. Estado de conservação do veículo
\end{tabular}


10. Conforto das cadeira

11. Temperatura interna do veículo

12. Espaço no ônibus para a movimentação dos passageiros

13. Espaço para bagagens dos passageiros

14. Facilidade de subida e descida do veículo

15. Dispositivos de segurança adequados ao uso (cinto de

segurança, extintor de incêndio, saída de emergência, etc)

16. Informações existentes nos veículos (alteração de itinerário e avisos diversos)

17. Ter canais de comunicação para o passageiro elogiar, reclamar e sugerir

18. Rapidez para trocar de ônibus dentro da empresa

19. Infraestrutura da rodoviária interna à empresa

20. Educação do motorista com os passageiros

21. Segurança passada pelos motoristas ao dirigir

22. Possibilidade de alteração do itinerário

23. Campainha do ônibus

24. Rapidez na solução de problemas com o ônibus na rua

A partir da Tabela 5, conclui-se que as características que mais necessitam da atenção por parte dos atores envolvidos são Tempo de viagem (3) e Respeito à capacidade de lotação do ônibus (4).

\section{CONCLUSÃO}

Este artigo apresentou uma análise da prestação do serviço de transporte fretado de empregados de uma grande empresa, levantando e confrontando as visões dos atores envolvidos, ou seja, do funcionário que utiliza o transporte, da empresa que presta o serviço e da empresa que o contrata, visando a proposição de um procedimento para avaliar a qualidade do serviço de transporte fretado de funcionários sob a visão dos agentes envolvidos.

É importante ressaltar que, enquanto a maioria das pesquisas existentes na Literatura utilizara somente a visão dos usuários, a presente pesquisa avalia a visão dos gestores da equipe de transporte da empresa contratante, dos usuários/funcionários da empresa contratante, dos técnicos administrativos e dos motoristas da empresa prestadora do serviço.

Ressalta-se, ainda, que as duas questões iniciais desta pesquisa foram plenamente respondidas, quais sejam: quais fatores permitem avaliar a qualidade do serviço de transporte urbano de empregados por uma frota de ônibus fretada? Como avaliar a qualidade do serviço de transporte fretado de empregados sob a ótica dos agentes envolvidos - usuários, contratante e prestadora do serviço?

Para responder à primeira questão, fez-se um levantamento bibliográfico dos estudos realizados sobre a qualidade de serviço de transporte de passageiros, visando identificar os principais atributos e características que influenciam a qualidade do transporte de passageiros em geral. A seguir, desdobrou-se as características do transporte de passageiros em características específicas para o serviço de transporte fretado de empregados, utilizando o desdobramento da qualidade (QFD), o que permitiu identificar as caraterísticas que permitem avaliar a qualidade do serviço de transporte urbano de empregados por uma frota de ônibus fretada, que estão apresentadas no Quadro 2. 
Em resposta à segunda questão, apresentou-se o procedimento proposto (Figura 3), que é uma contribuição para avaliação da qualidade do serviço de transporte fretado de funcionários por ônibus, que tem por base e promove inovações ao Modelo "GAP" de Qualidade dos Serviços de Parassuraman et al. (1988). Esse procedimento inova ao incluir a visão do prestador de serviço como terceiro agente no modelo. Inova também ao desdobrar o agente "cliente" em usuários e gestores do contrato e, ainda, o provedor do serviço em motoristas e técnicos administrativos. Como consequência dessas inovações, os GAPs no procedimento proposto estão rearranjados e apresentados na Figura 4.

Os resultados obtidos na aplicação do procedimento proposto mostraram o seu potencial na avaliação da qualidade do serviço de transporte fretado de funcionários, identificando as características de avaliação que se mostraram críticas na prestação do serviço e indicando as ações corretivas a serem implementadas pelos agentes responsáveis. Os dados coletados e analisados podem embasar, por exemplo, planos de ação de melhorias. Vale destacar a importância da manutenção da frequência de avaliação, ou seja, é importante manter a utilização deste procedimento de avaliação em um período de tempo pré-determinado, pois, assim, a empresa conservará resultados sempre atualizados.

Algumas limitações da pesquisa podem ser destacadas. Primeiramente, existiu a necessidade de suprimir a expectativa dos motoristas. Contudo, isto não prejudicou a aplicação do procedimento e também mostrou que a inclusão ou não deste agente pode ficar a critério do pesquisador. Outra limitação deve-se ao fato de que o questionário dos usuários foram enviados via email institucional, o que pode em última instância afetar o julgamento dos mesmos. Contudo, acredita-se que isto não invalidou a avaliação, visto que o número de respostas obtidas foram superiores à estatística mínima necessária, além de que não foi solicitada nenhuma identificação por parte dos usuários no link disponibilizado. 


\section{Procedure for evaluating the quality of the transportation service chartered of employees by bus by the perspective of passengers, service contractor and the service provider}

\section{ABSTRACT}

The purpose of this article is to propose a procedure to evaluate the quality of the freight transport service of employees and to establish a correlation between the view of the agents involved - users, contracting company and service provider. In order to do so, an analysis of quality GAPs was carried out, that is, from a bibliographical review one can raise characteristics that influence the quality of the passenger transport, and therefore, the differences of their perceptions could be identified, through of a field experiment. In this way, the characteristics and perceptions of the users, the contracting company and the employee transport service provider could be exposed, as well as an evaluation of the quality of the chartered transportation service of employees. This procedure innovates by including the service provider's view as the third agent in the model. It also innovates by deploying the "client" agent in contract users and managers and also the company hired by drivers and administrative technicians. As a consequence of these innovations, the GAPs were redefined and rearranged in the proposed procedure.

KEYWORDS: Quality. Quality services. Transportation systems. 


\section{REFERÊNCIAS}

ALEXANDRE, R. W. C. (2010). Preferências dos clientes de serviços especiais de transporte urbano por ônibus. Dissertação (Mestrado) - Programa de PósGraduação em Engenharia de Transportes, COPPE, Universidade Federal do Rio de Janeiro, Rio de Janeiro.

ANTUNES, E. M. (2009) Avaliação da qualidade do transporte público por ônibus sob o ponto de vista do usuário em cidades médias paranaenses. Dissertação (Mestrado) - Programa de Pós-Graduação em Engenharia Urbana, Universidade Estadual de Maringá, Maringá.

ANTUNES, E. M.; SIMÕES, F. A. (2013) Utilização da psicometria para avaliar a qualidade do serviço de transporte: um estudo de caso. Revista Gestão Industrial, v. 09, n. 02: p. 416-439. crossref

DE OÑA, J.; DE OÑA, R.; CALVO, F. J. (2012) A classification tree approach to identify key factors os transit service quality. Expert Systems with Applications, 39(12), 11164-11171. crossref

DE OÑA, J.; DE OÑA, R.; EBOLI, L.; MAZULLA, G. (2013) Perceived service quality in bus transit service: A structural equation approach. Transport Policy, 29, 219226. crossref

DELL'OLIO, L.; IBEAS, A.; CECIN (2011) The quality of service desired by public transport users. Transport Policy, 18(1), 217-227. crossref

EBOLI, L.; MAZZULA, G. (2011) A methodology for evaluating transit service quality based on subjective and objective measures from the passenger's point of view. Transport Policy, 18(1), 172-181. crossref

FREITAS, A. L. P. (2013) Assessing the quality of intercity Road transportation of passengers: $\mathrm{Na}$ exploratory study in Brazil. Transportation Research Part A: Policy and Practice, 49(2013), 379-392. crossref

FREITAS, A. L. P.; REIS, T. B. (2013) Avaliação do transporte público urbano realizado por ônibus: uma abordagem exploratória. Revista Produção Online, v.13, n. 3, p. 814-842, jul./set, Florianópolis. crossref

FREITAS, A. L. P.; REIS FILHO, C. A. C.; RODRIGUES, F. R. (2011) Avaliação da qualidade do transporte rodoviário intermunicipal de passageiros: uma abordagem exploratória. Transportes, v.19, n.3, p. 49-61. crossref 
JAMMAL, M. F. (2010) Análise dos requisitos de qualidade do transporte coletivo urbano de São José do Rio Preto - SP usando o método QFD. 2010. Dissertação (Mestrado) - Programa de Pós-Graduação em Engenharia Urbana, Universidade Federal de São Carlos, São Carlos.

KORZENOWSKI, A. L.. et al. (2008) QFD no serviço de transporte coletivo urbano por ônibus utilizando análise de componentes principais para priorização dos requisitos dos usuários. In: CONGRESSO DE PESQUISA E ENSINO EM TRANSPORTES, 22, 2008, Fortaleza. Anais... Fortaleza: ANPET.

MACHADO, M. D.; QUEIROZ, T. R.; MARTINS, M. F. Mensuração da qualidade de serviço em empresas de fastfood. Gestão \& Produção, v.13, n.2, p. 261-270, maio-ago., 2006.

MORAIS, J. S. (2012). Proposta de método para avaliação da qualidade do transporte público urbano por ônibus utilizando a Teoria das Representações Sociais. Dissertação (Mestrado) - Departamento de Engenharia Civil e Ambiental, Universidade de Brasília, Brasília.

OLIVEIRA, R. R. (2006) Aplicação da metodologia QFD no transporte rodoviário interestadual de passageiros em Vitória/ES. Dissertação (Mestrado) Universidade Federal do Espírito Santo, Faculdade de Engenharia Civil, Arquitetura e Urbanismo, Vitória.

PARASURAMAN, A., ZEITHAML, V.A., BERRY, L.L. SERVQUAL: a multiple- item scale for measuring consumer perceptions of service quality, Journal of Retailing, vol. 64, no 1, pp. 12-40, 1988.

PARASURAMAN, A., ZEITHAML, V.A., BERRY, L.L. A conceptual model of service quality and its implications for future research, Journal of Marketing, pp.41-50, 1985. crossref

PÊGO, F. F.; ZANDONADE, E.; MORAIS NETO, G. C. (2008) Aplicação da metodologia QFD no transporte coletivo urbano de passageiros. Revista dos Transportes Públicos - ANTP. Ano $30.2^{\circ}$ trimestre.

RODRIGUES, A.; JUNIOR, C. A. P. S.; FONTENELE, H. B. (2010) Uma contribuição à análise da qualidade do transporte público urbano por ônibus. Anais do XXIV Congresso de Pesquisa e Ensino em Transportes, ANPET, Salvador. 
Recebido: 14 jul 2017

Aprovado: 16 mar 2018

DOI: 10.3895/gi.v14n1.6703

Como citar:

SOUZA, N. B. P.; MORAIS NETO, G. C. M.; CARDOSO, P. A. Procedimento para avaliação da qualidade do serviço de transporte fretado de funcionários por ônibus sob a ótica do usuário, empresa contratante e prestadora do serviço. R. Gest. Industr., Ponta Grossa, v. 14, n. 1, p. 101-122, jan./mar. 2018. Disponível em: <https://periodicos.utfpr.edu.br/rgi>. Acesso em: XXX.

Correspondência:

Noéle Bissoli Perini de Souza

Rodovia BR 101, km 65, 2121, Santo Antônio, São Mateus, Espírito Santo, Brasil.

Direito autoral: Este artigo está licenciado sob os termos da Licença Creative Commons-Atribuição 4.0

Internacional. 